\title{
MULTI-OBJECTIVE OPTIMIZATION OF RETAINING WALL USING GENETIC ALGORITHM
}

\author{
Filip Dodigović ${ }^{1}$, Krešo Ivandić ${ }^{*}$, Jasmin Jug ${ }^{1}$, Krešimir Agnezović ${ }^{1}$ \\ ${ }^{1}$ University of Zagreb, Faculty of Geotechnical Engineering, Hallerova aleja, 742000 Varaždin, Croatia \\ *E-mail of corresponding author: kreso.ivandic@gfv.unizg.hr
}

\begin{abstract}
The paper investigates the possibility of applying the genetic algorithm NSGA-II to optimize a reinforced concrete retaining wall embedded in saturated silty sand. Multi-objective constrained optimization was performed to minimize the cost, while maximizing the overdesign factors $(O D F)$ against sliding, overturning, and soil bearing resistance. For a given change in ground elevation of $5.0 \mathrm{~m}$, the width of the foundation and the embedment depth were optimized. Comparing the algorithm's performance in the cases of two-objective and three objective optimizations showed that the number of objectives significantly affects its convergence rate. It was also found that the verification of the wall against the sliding yields a lower ODF value than verifications against overturning and soil bearing capacity. Because of that, it is possible to exclude them from the definition of optimization problem. The application of the NSGA-II algorithm has been demonstrated to be an effective tool for determining the set of optimal retaining wall designs.
\end{abstract}

Keywords: Geotechnical analysis, NSGA-II, optimization, retaining wall, Eurocode 7.

\begin{tabular}{c}
\hline $\begin{array}{c}\text { Received: 01.09.2021. / Accepted: 15.11.2021. } \\
\text { Published online: 01.12.2021. }\end{array}$ \\
Professional paper \\
https://doi.org/10.37023/ee.8.1-2.8
\end{tabular}

\section{INTRODUCTION}

The classic approach to geotechnical design is an iterative process to find the optimal solution that meets prescribed safety margins at a minimal cost. Complex geotechnical analyses often involve many decision variables and limit states verifications, resulting in a large number of feasible designs in the design space. In the classical approach, the search for the optimal designs in the solution space is done manually, which may lead to the selection of a suboptimal design. The use of multi-objective optimization using the NSGA-II genetic algorithm enables the automated search for optimal designs in the entire solution space. The algorithm is based on the dominance principle (Čupić, 2013), and it produces a set of non-dominated designs, referred to as the Pareto front.

Several authors explored the possibility of optimizing geotechnical structures by combining various optimization techniques with reliability theory (Dodigović et al., 2021; Gong et al., 2017, 2014; Juang et al., 2012; Juang and Wang, 2013; Khoshnevisan et al., 2016, 2014a, 2014b). Numerous advantages of such an approach have been emphasized in the literature. Still, due to the complexity of applying structural reliability theory principles, it is not often applied in engineering practice. Optimization of geotechnical structures using the NSGA-II algorithm can be performed without the use of reliability theory. For example, in this case, the overdesign factors (ODF) (Frank et al., 2005) can be maximized while minimizing the cost of the structure.

Islam and Rokonuzzaman (2018) use a genetic algorithm to optimize the design of a footing. They compare the obtained results with the results of the classical approach and conclude that the application of a genetic algorithm can reduce the structure cost by $68 \%$.

Yazadani et al. (2016) investigate the ant colony optimization method for raft piled foundation design. They developed the ACO algorithm for finding optimal solutions of piled-raft foundations. Shahin (2015) investigates the applicability of evolutionary computation for use in complex geotechnical analyzes. They evaluate the application of evolutionary polynomial regression (ERP) to various geotechnical tasks. The obtained results are compared with the results of in-situ tests, from which they conclude that the studied method is suitable for use in complex geotechnical analyzes. This paper investigates the possibility of applying NSGA-II (Non-Dominated Sorting Genetic Algorithm II) to optimize the embedment depth and foundations width of a retaining wall. In this case, the feasible design space consists of all designs that satisfy the ultimate limit state criteria according to Eurocode 7, design approach 3 (European Committee for Standardization, 2012). In the optimization procedure, materials and actions are characterized by mean, characteristic and design values (European Committee for Standardization, 2011). The result of the NSGA-II algorithm is a Pareto front from which the final design is selected. 


\section{MATERIALS AND METHODS}

\subsection{Retaining wall geometry and geotechnical properties of soil}

Geotechnical analyzes were carried out on the reinforced concrete retaining wall with the geometry showed in Figure 1. In accordance with the ultimate limit state criteria, the wall is designed for a given change in ground elevation of $5.0 \mathrm{~m}$. The wall is embedded in a saturated silty sand (SM). A drainage layer behind the wall consists of well graded gravel $(\mathrm{GW})$. Water pressure on the stem is not expected due to the drainage pipe installed at its base.

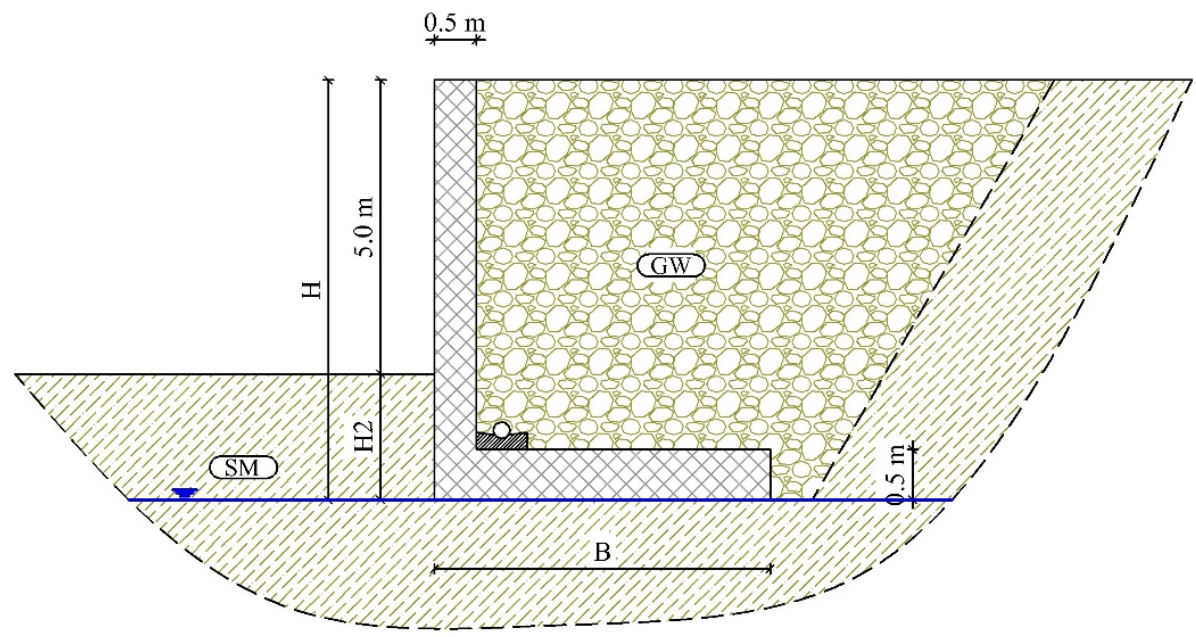

Figure 1. Geometry of the wall

Table 1 summarizes the features of the geotechnical parameters used in the analyses. Coefficients of variation were chosen in accordance with the recommendation of Duncan (2000). Geotechnical random variables are assumed to be normally distributed. From the mean values, the characteristic values of geotechnical parameters were calculated according to the following equation Schneider (1999):

$$
X_{k}=X_{m} \cdot\left(1-0.5 \cdot \operatorname{COV}_{X}\right)
$$

where:

$X \quad$ is the variable symbol,

$X_{m} \quad$ is the mean value of $\mathrm{X}$,

$\operatorname{COV}_{X}$ is the coefficient of variation of $\mathrm{X}$.

Design values are calculated from the characteristic values using partial factors according to Eurocode 7, design approach 3 .

Table 1. Statistical properties of geotechnical random variables

\begin{tabular}{|c|c|c|c|c|}
\hline \multirow{2}{*}{ SYMBOL } & \multirow{2}{*}{ DESCRIPTION } & \multirow{2}{*}{$\begin{array}{c}\text { SOIL UNIT } \\
\text { WEIGHT } \\
{\left[\mathrm{kN} / \mathrm{m}^{3}\right]} \\
\end{array}$} & \multicolumn{2}{|c|}{$\begin{array}{l}\text { EFFECTIVE ANGLE OF } \\
\text { INTERNAL FRICTION }\end{array}$} \\
\hline & & & $\boldsymbol{\phi}_{m}^{\prime}\left[^{\circ}\right]$ & $\operatorname{cov}_{\phi^{\prime}}$ \\
\hline GW & Well-graded gravel & 20 & 33 & 0.1 \\
\hline ML & Silty sand & 19 & 28 & 0.1 \\
\hline
\end{tabular}

\subsection{Verification of ultimate limit states according to Eurocode 7}

Figure 2 shows the forces acting on the retaining wall. Up to the freezing depth, the effect of passive soil resistance is neglected. The force $V_{d}$ is the sum of the weight of the soil above the foundation and the weight of the retaining wall. Since the vertical force is eccentric, the bearing capacity is calculated for the effective area of the footing. 


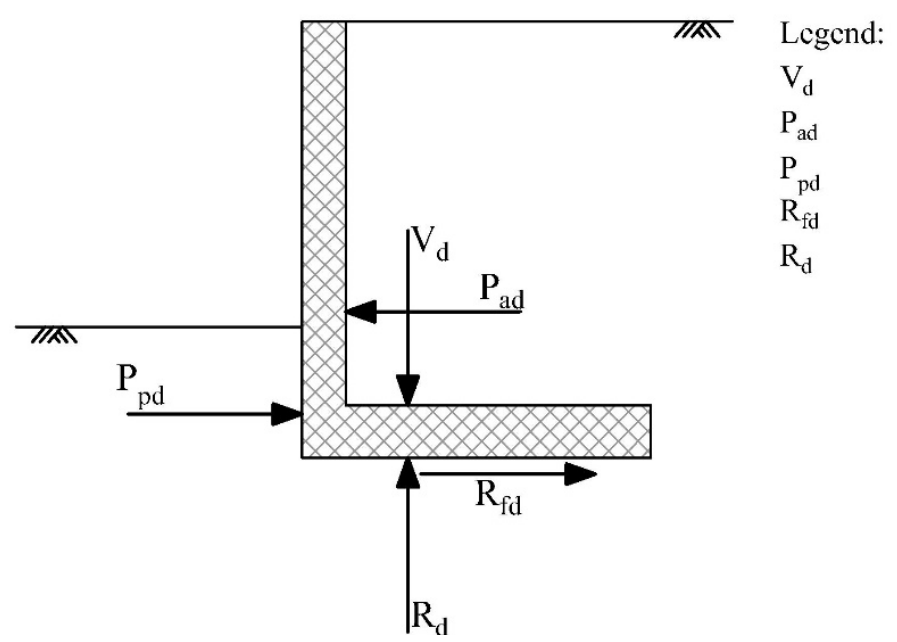

design vertical action

design active earth thrust

design passive resistance

design resistance on the soil-wall contact

design bearing resistance

Figure 2. Forces acting on the retaining wall

Verification of bearing capacity and resistance against sliding is carried out using Equations 2 and 3.

$$
\begin{gathered}
V_{d} \leq R_{d} \\
P_{a d} \leq F_{f d}+P_{p d}
\end{gathered}
$$

To establish the influence of each ultimate limit state on the required minimum wall dimensions, preliminary geotechnical analyses were conducted. The findings of these investigations are not included in this paper. Due to a negligible influence, it was determined that the verification against overturning may be excluded from subsequent analyses.

Design values of active earth thrust $P_{a d}$, passive resistance $\left(P_{p d}\right)$, resistance at wall-soil contact $\left(R_{f d}\right)$, vertical action $\left(V_{d}\right)$ and bearing capacity $\left(R_{d}\right)$ are determined using Equations 4-8.

Where:

$$
\begin{gathered}
P_{a d}=K_{a d} \cdot \gamma_{s} \cdot \frac{H^{2}}{2} \cdot L \\
P_{p d}=K_{p d} \cdot \gamma_{s} \cdot \frac{H^{2}}{2} \cdot L \\
V_{d}=\gamma_{G, \text { unfav }} \cdot V_{k}=\gamma_{G, \text { unfav }} \cdot G_{\text {wall }}+G_{\text {soil }} \\
R_{f d}=V_{k} \cdot 0.67 \cdot \tan \phi_{d} \cdot B \cdot L \\
R_{d}=\left[q^{\prime} N_{q} S_{q}+0.5 \gamma^{\prime} B^{\prime} N_{\gamma} s_{\gamma}\right] \cdot A^{\prime}
\end{gathered}
$$

$K_{a d}$ and $K_{p d}$ are Rankine's earth pressure coefficients,

$\gamma_{S}$ is the weight of the gravel,

$\gamma_{G \text {,unfav }}$ is the partial factor for an unfavorable permanent action,

$V_{k}$ is the characteristic value of vertical load,

$G_{\text {wall }}, G_{\text {soil }}$ are weights of the wall and soil,

$\phi_{d}$ is the design value of angle of internal friction of gravel,

$q^{\prime}$ the design effective overburden pressure at the level of the foundation base,

$N_{q}, N_{\gamma}$ are dimensionless factors for the bearing capacity,

$s_{q}, s_{\gamma}$ are dimensionless factors for the shape of foundation,

$A^{\prime}$ is the design effective foundation area.

\subsection{The optimization problem}

The decision variables in the optimization task are foundation width (B) and wall embedment depth (H2). Two-objectives and three-objective optimizations were performed. In the first case, the wall cost is minimized while the ODF for wall sliding $\left(O D F_{s l}\right)$ is maximized. In addition to the above, the ODF for wall bearing capacity $\left(O D F_{b c}\right)$ is maximized in the second case. Design space is divided into feasible and infeasible design spaces, setting up four optimization constraints. 
The optimization problem can be set up as follows:

\begin{tabular}{ll}
\hline Find: & $\mathrm{d}=[\mathrm{B}, \mathrm{H} 2]$ \\
Subject to: & $B \in\{3.0 \mathrm{~m}, 3.1 \mathrm{~m}, \ldots, 8.0 \mathrm{~m}\}$ and \\
& $H 2 \in\{0.8 \mathrm{~m}, 0.9 \mathrm{~m}, \ldots, 2.5 \mathrm{~m}\}$ \\
& $O D F_{s l} \leq 1.0$ \\
& $O D F_{b c} \leq 1.0$ \\
& $A_{s 1} \leq A_{s, \max }$ \\
& Maximizing $O D F_{s l}$ and $O D F_{b c}$ \\
Objective: & Minimizing cost of the retaining wall \\
\end{tabular}

The cost of the foundation was estimated using the following equation:

$$
Z=Q_{e} c_{e}+Q_{f} c_{f}+Q_{c} c_{c}+Q_{r} c_{r}
$$

Where $Q_{e}, Q_{f}, Q_{c}$ and $Q_{r}$ are quantities of excavation, compacted backfill, concrete and reinforcement, respectively, $c_{e}, c_{f}, c_{c}$ and $c_{r}$ are the associated unit prices. Unit prices are expressed in Croatian kuna (HRK). They are estimated according to the author's experience.

\subsection{NSGA-II algorithm}

Multi-objective optimization is performed using the NSGA-II algorithm (Deb, 2001). It is a variant of the genetic algorithm that applies the principle of dominance to the optimization problem. In the algorithm, parents are selected from the parent population and combined by crossover. The mutation operator is applied to the solutions obtained by the crossover operaton. Then, the procedure is repeated until a children population with the same number of elements as the parent population built. The parent population is deleted, and children become new parents (Čupić, 2013). The procedure is carried out until the termination criterion is met. In this paper, the number of generations is selected as the termination criterion. The convergence of the algorithm was checked using a hypervolume indicator (Beume et al., 2007). The NSGA-II algorithm flowchart is shown in Figure 3. Optimization was performed using the Python programming language and the Pymoo library (Blank and Deb, 2020).

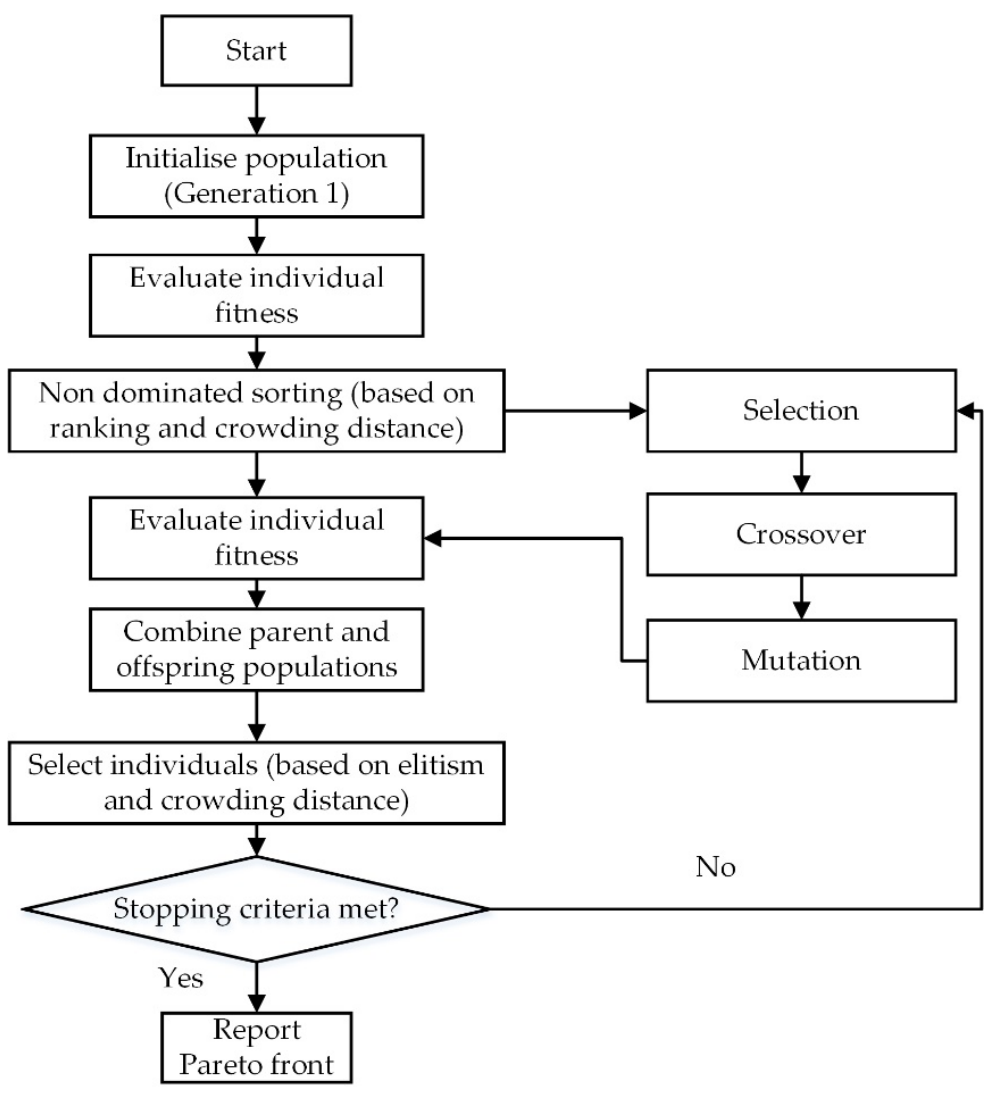

Figure 3. A flowchart of the NSGA-II algorithm 


\section{RESULTS}

Figure 4a shows the Pareto front for the case of three-objective optimization, and Figure $4 \mathbf{b}$ shows its projection on the plane $O D F_{s l}-O D F_{b c}$. Design space comprises 738 designs, of which 290 are in the Pareto front. The $O D F_{s l}$ range is from 1.0 to 2.0 , and $O D F_{b c}$ ranges from 1.3 to 3.5. The lowest construction price is 14700 , and the highest is $26000 \mathrm{HRK} / \mathrm{m}$ '.

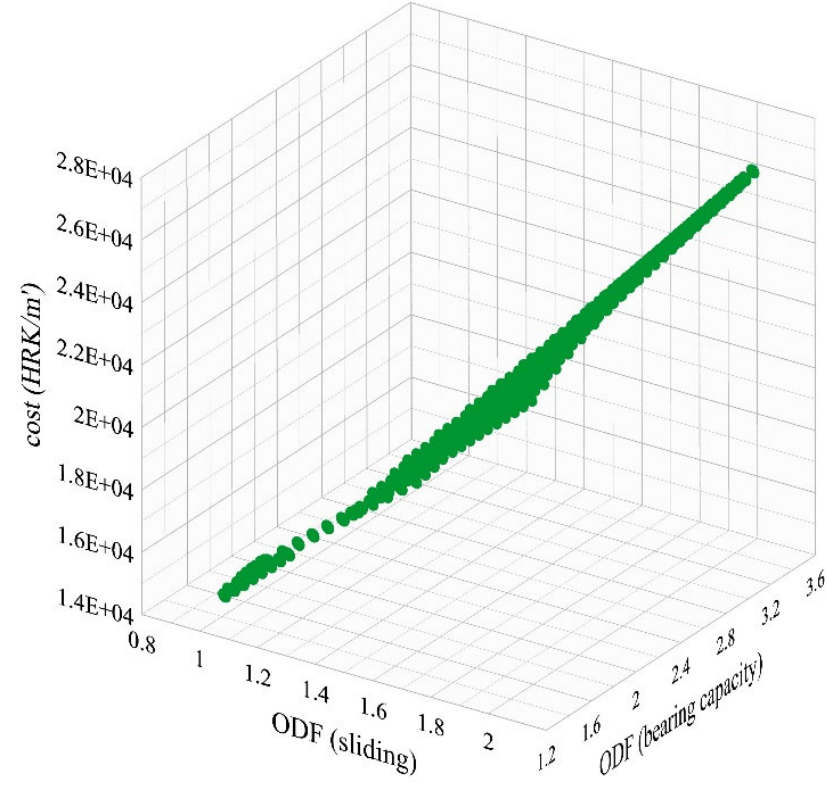

(a)

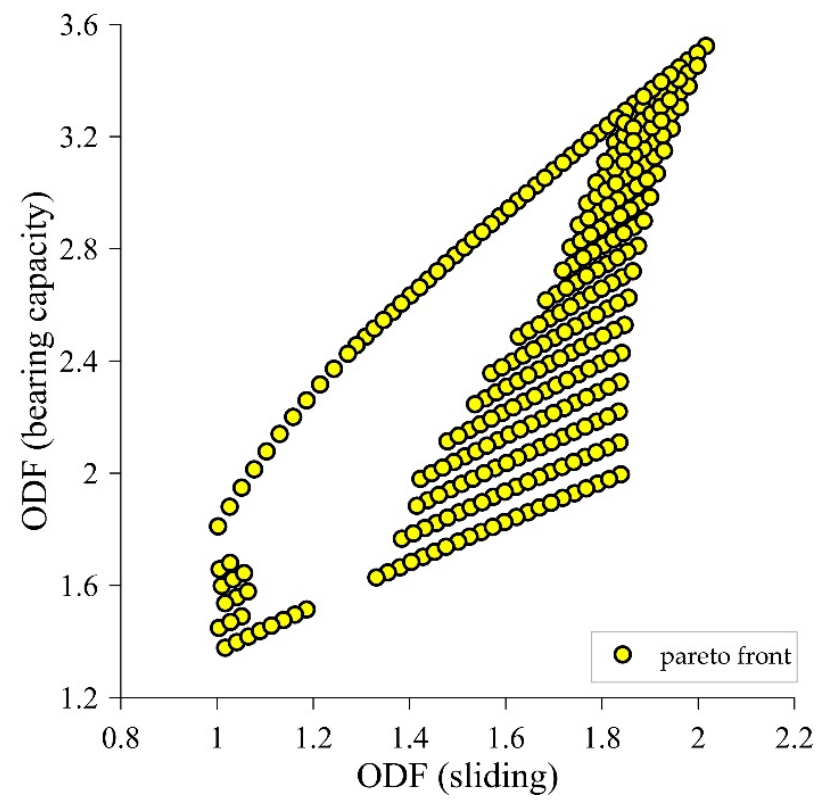

(b)

Figure 4. Pareto front for the case of three-objective optimization (a), projection of the Pareto front on the plane $O D F_{s l}-O D F_{b c}(b)$

Figure 5 shows the Pareto front determined by two-objective optimization that comprises 63 non-dominated designs. Out of a total of 738 designs, 26 are infeasible, and 712 are feasible designs. The values of $O D F_{s l}$ and construction costs are the same as in the case of three-objective optimization.

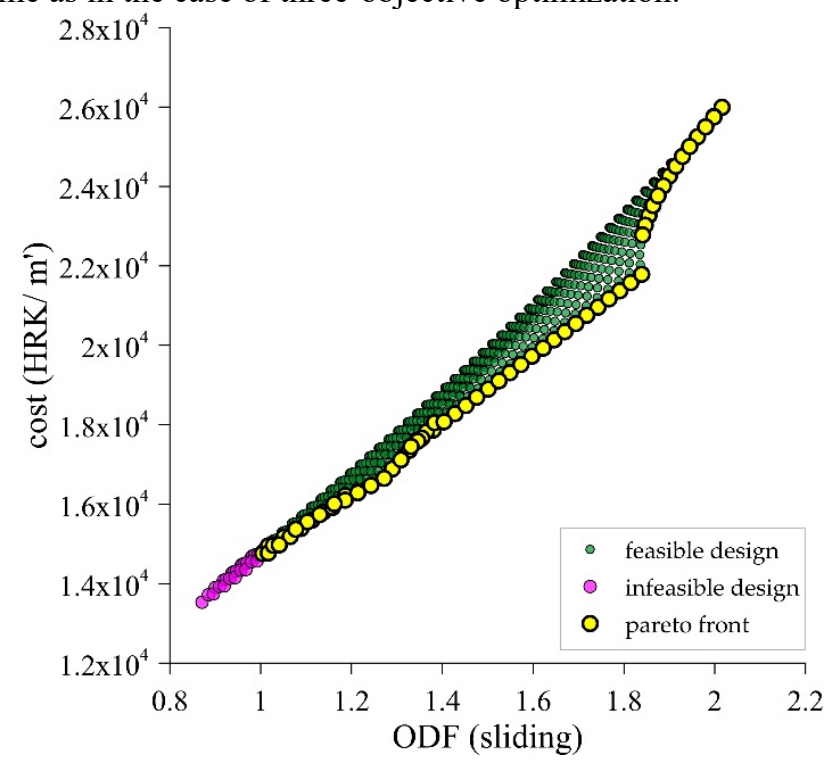

Figure 5. Pareto front along with feasible and infeasible designs for the case of two-objective optimization 
Figures 6a and $\mathbf{6 b}$ shows the non-dominant designs in the decision space, resulting from two-objective and three-objective optimization. For the same number of decision variables, there is a significant difference in the number of non-dominated solutions between the two considered examples.

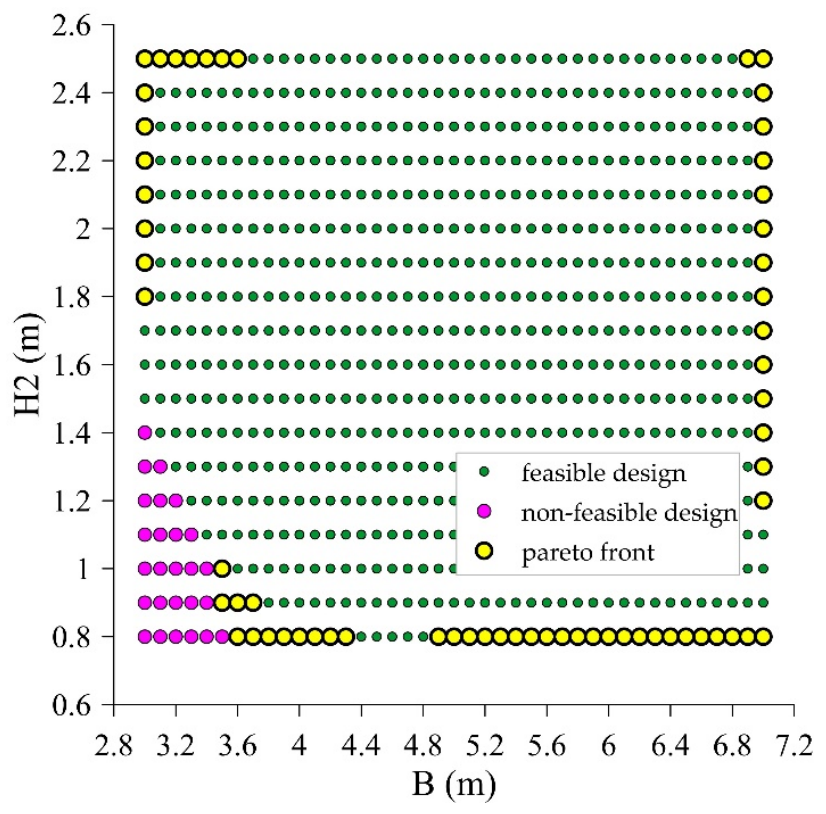

(a)

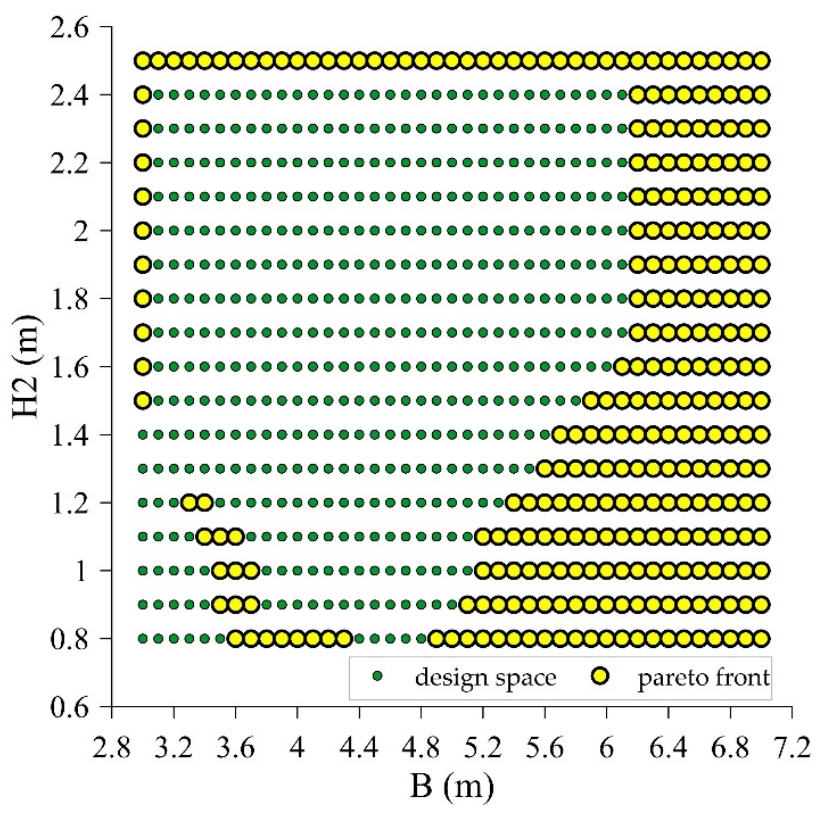

(b)

Figure 6. Pareto front in decision space for the case of two-objective (a) and three-objective (b) optimization.

Figures 7a and 7b shows the convergence of the NSGA-II algorithm for the two-objective and three-objective optimization cases. In the first case, the algorithm converged after 480, and in the second after 835 generations.

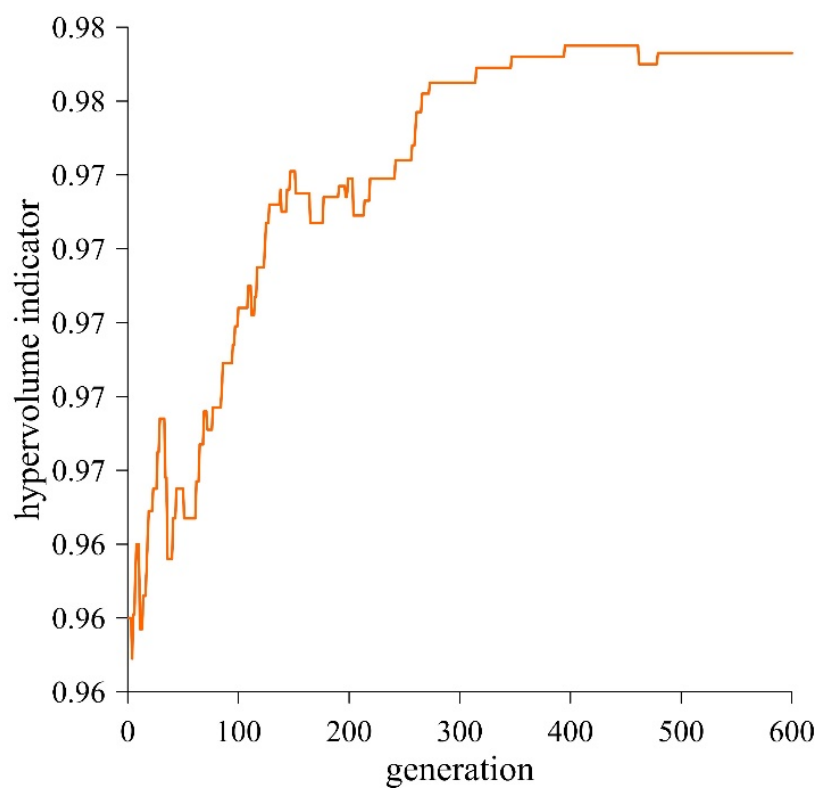

(a)

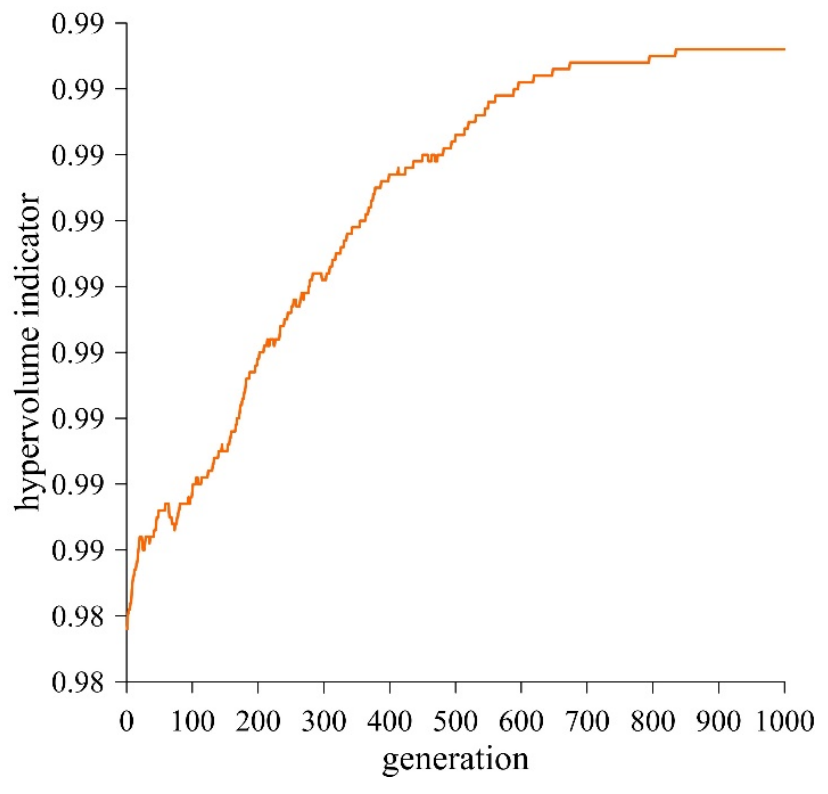

(b)

Figure 7. Convergence of the NSGA-II algorithm for the case of two-objective (a) and three-objective (b) optimization 


\section{DISCUSSION AND CONCLUSIONS}

The paper investigates the possibility of applying the genetic algorithm NSGA-II to optimize the design of a reinforced concrete retaining wall. The wall is embedded in a saturated silty sand (SM), with the groundwater level at the base of the footing. A drainage layer of well-graded gravel $(\mathrm{GW})$ is installed behind the wall. For a $5.0 \mathrm{~m}$ change in ground elevation, the foundation width and embedment depth are optimized. A minimum embedment depth is $80 \mathrm{~cm}$ and is determined from the conditions related to the depth of soil freezing. To harmonize the results with Eurocode 7, four constraints are defined in the optimization problem. The goal of optimization is to determine a set of non-dominant designs, i.e., the Pareto front.

Two-objective and three-objective optimizations were performed with the aim of minimizing costs and maximizing overdesign factors for wall verification against sliding and bearing capacity. An additional objective in the three-objective optimization was found to significantly affect the convergence rate of the NSGA-II algorithm. In the case of two-objective optimization, the algorithm converged after 480 and three-objective after 835 generations, as shown in Figures 7a and 7b. Figures 6a and $6 \mathbf{b}$ shows that the Pareto front obtained by performing three-objective optimization consists of Pareto front of two-objective optimization with the addition of the designs that have higher $O D F_{b c}$ values for the same cost. Only 26 of the 738 designs are infeasible, as shown in Figure 5. The reasons for that are appropriate assumptions of minimum and maximum values of decision variables. The difference in the number of designs in the Pareto front can be seen in Figures 6a and 6b. Twoobjective optimization yielded 63 optimal designs, while three-objective optimization yielded 290 . The ultimate limit state verification against sliding controls the wall designs in the case of the retaining wall studied in this paper. Because of this reason, objectives related to verifications of other ultimate limit states are excluded from the optimization problem. The optimization procedure and graphical representations of the Pareto front were greatly simplified by reducing the number of objectives.

From the obtained Pareto front, the final design is selected. There are various options for selecting a final design. In the literature, the knee point concept is frequently employed (Gong et al., 2017; Ravichandran and Shrestha, 2020; Zhou et al., 2020). According to this concept, the final design is selected in the knee point Pareto front. It is possible to choose a final solution by reducing the multi-objective optimization problem to a singleobjective problem by forming a composite objective function as the weighted sum of the objectives (Deb, 2001).

The implementation of the genetic algorithm NSGA-II allows for the quick and straightforward determination of the Pareto front in the case of retaining wall optimization. Preliminary geotechnical analyses are proposed to reduce the number of objectives and decision variables for defining the optimization problem. In this way, it is possible to simplify optimization, speed up the algorithm's convergence, and facilitate the selection of the final design.

\section{REFERENCES}

Beume, N., Naujoks, B., \& Emmerich, M. (2007). SMS-EMOA: Multiobjective selection based on dominated hypervolume. European Journal of Operational Research, 181(3), 1653-1669. https://doi.org/10.1016/j.ejor.2006.08.008

Blank, J., \& Deb, K. (2020). Pymoo: Multi-Objective Optimization in Python. IEEE Access, 8, 89497-89509. https://doi.org/10.1109/ACCESS.2020.2990567

Čupić, M. (2013). Prirodom inspirirani optimizacijski algoritmi. Metaheuristike. Zagreb, Croatia: Faculty of Elecetrical Engineering and Computing Zagreb.

Deb, K. (2001). Multi-Objective Optimization using Evolutionary Algorithms Kalyanmoy. John Wiley \& Sons, 16(9), 1689-1699.

Dodigović, F., Ivandić, K., Kovačević, M.-S., \& Soldo, B. (2021). Modified, Reliability-Based Robust Geotechnical Design Method, in Accordance with Eurocode 7. Applied Sciences, 11(18), 8423. https://doi.org/10.3390/app11188423

Duncan, J. M. (2000). Factors of Safety and Reliability in Geotechnical Engineering. Journal of Geotechnical and Geoenvironmental Engineering, 126(April), 307-316. https://doi.org/https://doi.org/10.1061/(ASCE)10900241(2000)126:4(307)

European Committee for Standardization. (2011). Eurocode: Basis of structural design (EN 1990:2002+A1:2005+A1:2005/AC:2010).

European Committee for Standardization. (2012). Eurocode 7: Geotechnical design -- Part 1: General rules (EN 1997-1:2004+AC:2009).

Frank, R., Bauduin, C., Driscoll, R., Kavvadas, M., Ovesen, N. K., Orr, T., Schuppener, B., \& Gulvanessian, H. (2005). Designers' Guide to EN 1997-1 Eurocode 7: Geotechnical Design - General Rules (H. Gulvanessian, Ed.). Thomas Telford Publishing. https://doi.org/10.1680/dgte7.31548

Gong, W., Huang, H., Juang, C. H., \& Wang, L. (2017). Simplified-robust geotechnical design of soldier pileanchor tieback shoring system for deep excavation. Marine Georesources \& Geotechnology, 35(2), 157-169. https://doi.org/10.1080/1064119X.2015.1120369 
Gong, W., Khoshnevisan, S., \& Juang, C. H. (2014). Gradient-based design robustness measure for robust geotechnical design. Canadian Geotechnical Journal, 51(11), 1331-1342. https://doi.org/10.1139/cgj-2013-0428

Islam, M. S., \& Rokonuzzaman, M. (2018). Optimized design of foundations: an application of genetic algorithms. Australian Journal of Civil Engineering, 16(1), 46-52. https://doi.org/10.1080/14488353.2018.1445437

Juang, C. H., \& Wang, L. (2013). Reliability-based robust geotechnical design of spread foundations using multi-objective genetic algorithm. Computers and Geotechnics, 48, 96-106. https://doi.org/10.1016/j.compgeo.2012.10.003

Juang, C. H., Wang, L., Atamturktur, S., \& Luo, Z. (2012). Reliability-based robust and optimal design of shallow foundations in cohesionless soil in the face of uncertainty. Journal of GeoEngineering, 7(3), $75-87$. https://doi.org/10.6310/jog.2012.7(3).1

Khoshnevisan, S., Gong, W., Wang, L., \& Juang, C. H. (2014a). Robust design in geotechnical engineering an update. Georisk, 8(4), 217-234. https://doi.org/10.1080/17499518.2014.980274

Khoshnevisan, S., Gong, W., Wang, L., \& Juang, C. H. (2014b). Robust design in geotechnical engineering an update. Georisk: Assessment and Management of Risk for Engineered Systems and Geohazards, 8(4), 217234. https://doi.org/10.1080/17499518.2014.980274

Khoshnevisan, S., Wang, L., \& Juang, C. H. (2016). Simplified procedure for reliability-based robust geotechnical design of drilled shafts in clay using spreadsheet. Georisk: Assessment and Management of Risk for Engineered Systems and Geohazards, 10(2), 121-134. https://doi.org/10.1080/17499518.2016.1146305

Ravichandran, N., \& Shrestha, S. (2020). Performance- and cost-based robust design optimization procedure for typical foundations for wind turbine. International Journal of Geotechnical Engineering, 14(4), 395-408. https://doi.org/10.1080/19386362.2018.1428387

Schneider, H. R. (1999). Definition and determination of characteristic soil properties. Fourteenth International Conference on Soil Mechanics and Foundation Engineering. Proceedings, 2271-2274. https://www.issmge.org/uploads/publications/1/31/1997_04_0032.pdf

Shahin, M. A. (2015). Use of evolutionary computing for modelling some complex problems in geotechnical engineering. Geomechanics and Geoengineering, 10(2), 109-125. https://doi.org/10.1080/17486025.2014.921333

Yazdani, H., Hatami, K., \& Khosravi, E. (2013). Ant Colony Optimization Method for Design of Piled-Raft Foundations (DFI 2013 Student Paper Competition Winner). DFI Journal - The Journal of the Deep Foundations Institute, 7(2), 17-27. https://doi.org/10.1179/dfi.2013.7.2.002

Zhou, X., Huang, W., Li, J., \& Chen, D. (2020). Robust Geotechnical Design for Soil Slopes considering Uncertain Parameters. Mathematical Problems in Engineering, 2020, 1-11. https://doi.org/10.1155/2020/5190580 